\title{
Impact of Block Length and Temperature over Self-Assembling Behavior of Block Copolymers
}

\author{
Samia A. Kosa, ${ }^{1}$ Laila M. Al-Harbi, ${ }^{1}$ Musa Kaleem Baloch, ${ }^{2}$ \\ Irfan Ullah, ${ }^{2}$ and Elsayed H. El-Mossalamy ${ }^{3}$ \\ ${ }^{1}$ Department of Chemistry, Faculty of Science, King Abdulaziz University, P.O. Box 80203, \\ Jeddah 21589, Saudi Arabia \\ ${ }^{2}$ Department of Chemistry, University of Sargodha Sub-Campus Bhakkar, Bhakkar, Pakistan \\ ${ }^{3}$ Department of Chemistry, Faculty of Science, Benha University, Benha, Egypt
}

Correspondence should be addressed to Samia A. Kosa; skousah@kau.edu.sa

Received 6 December 2015; Revised 26 March 2016; Accepted 7 April 2016

Academic Editor: Beng T. Poh

Copyright (C) 2016 Samia A. Kosa et al. This is an open access article distributed under the Creative Commons Attribution License, which permits unrestricted use, distribution, and reproduction in any medium, provided the original work is properly cited.

\begin{abstract}
Self-assembling behavior of block copolymers having water-soluble portion as one of the blocks plays key role in the properties and applications of the copolymers. Therefore, we have synthesized block copolymers of different block length and investigated their self-assembling behavior with reference to concentration and temperature using surface tension and conductance measurement techniques. The results obtained through both techniques concluded that critical micelles concentration (CMC) was decreased from 0.100 to $0.078 \mathrm{~g} / \mathrm{dL}$ with the increase in length of water insoluble block and 0.100 to $0.068 \mathrm{~g} / \mathrm{dL}$ for the increased temperature. $\Delta G_{\text {mic }}$ was also decreased with the increase in temperature of the system, concluding that the micellization process was encouraged with the increase in temperature and block length. However, $\Delta H_{\text {mic }}$ values were highest for short block length copolymer. The surface excess concentration obtained from surface tension data concluded that it was highest for short block length and vice versa and was increased with the increase in temperature of the system. However, the minimum area per molecule was largest for highest molecular weight copolymers or having longest water insoluble block and decreases with the increase in temperature.
\end{abstract}

\section{Introduction}

Amphiphilic block copolymers (ABCs) are of considerable interest due to their applications as emulsifiers, dispersants, stabilizers, compatibilizers, and so forth and are used alone or as a mixture with homopolymers and/or surfactants [1-4]. These ABCs have the capability to self-assemble in solution forming nanostructures with various morphologies. These morphologies can be like spherical micelles, worm micelles, and vesicles or can be more complex such as multicompartment micelles, toroids, and helices depending upon the concentration and structure of copolymers [5]. The potential application of such material is in the field of drug delivery, membranes, nanoreactors, smart polymers, micelles, and gels. Such polymers are normally composed of water-soluble polymer (like poly(ethylene glycol) (PEG), poly(ethylene oxide) (PEO), and poly(propylene oxide) (PPO)) as one of the blocks and the other water insoluble or partially soluble blocks and are due to self-assembled micelles and hence the scientists are investigating such polymers with special reference to micellar phase structures $[1,2]$. On the other hand, the synthesis of block copolymers with well-defined architecture and chain length and distribution requires efficient controlled/"living" polymerization methods [5-10]. More recently block copolymers were obtained by "living" or "controlled" free-radical polymerization [11-13] or using atom transfer radical polymerization (ATRP) to prepare well-defined PS-b-PEO diblock and PS-b-PEO-bPS triblock copolymers [14-19]. The purpose of this study was to synthesize well-defined diblock copolymers PS-bPEO according to scheme established in this lab [19] and to investigate the impact of molecular chain length of one of the blocks with reference to their association behavior using various techniques. 


\section{Experimental}

2.1. Materials. $\alpha$-Chlorophenylacetyl chloride (95\%, Fluka) was distilled using Vigreux column. PEO monomer ethyl ether (MePEO) 5000 (Aldrich) was dried by employing azeotropic distillation with toluene in a water separator. Inhibitors in styrene (St) were removed by passing the monomer through an aluminum oxide column. $\mathrm{CuBr}(98 \%$, Aldrich) and 2,2-bipyridine (bipy) (Aldrich) were used as received. Polymerization was carried out in nitrogen atmosphere. Though the synthesis was carried out as per details provided in [19] briefly, poly(ethylene oxide) macroinitiator PEO (MePEO, Mn = 5.000) was dissolved in toluene and refluxed for $12 \mathrm{~h}$ in water separator. Dried solution of MePEO (7.06 mmol in $100 \mathrm{~cm}^{3}$ toluene) was treated with $28.24 \mathrm{mmol}$ of $\alpha$-Chlorophenylacetyl chloride and refluxed for $24 \mathrm{~h}$. The solvents and volatiles were removed under high vacuum [15] and the residue was dissolved in $150 \mathrm{~cm}^{3}$ methylene chloride and stirred over $\mathrm{K}_{2} \mathrm{CO}_{3}$; the solvent was removed and the residue was dried. For purification purpose, the macroinitiator was dissolved in $100 \mathrm{~cm}^{3}$ toluene and reprecipitated into hexane and isolated by filtration and dried to constant weight. The required stoichiometry ratio of initiator, $\mathrm{CuBr}_{2}$, bipy, and monomer (styrene) was taken into a Schlenk glass tube and the mixture was degassed thrice under vacuum and filled under pressure with nitrogen before immersing in an oil bath at $130^{\circ} \mathrm{C}$. The polymerization was terminated by cooling the system rapidly to room temperature. The product was dissolved in Dichloromethane and precipitated into hexane. The polymer was isolated by filtration and dried to constant weight. By varying the amount of styrene monomer and initiator, block copolymer (PS-b-PEO) with different PS block length was synthesized.

2.2. Surface Tension Measurement. The surface tension is the technique which is very sensitive to micellization behavior of copolymers and hence this technique has been employed for the estimation of CMC of the copolymers under investigation. The copolymer was dissolved in water and the surface tension of the solution was measured under atmospheric pressure by the ring method [20] using TE3 LAUDA tensiometer, supplied by LAUDA, Germany. The platinum ring was thoroughly cleaned and flame-dried before each measurement. To determine the surface tension, the vertically hung ring was dipped into the liquid and then subsequently pulled out. The maximum force required to pull the ring through the interface was taken as the surface tension, $\gamma(\mathrm{mN} / \mathrm{m})$. The tensiometer was calibrated with pure water at $298 \mathrm{~K}$ before use. In all cases, more than three successive measurements were carried out, and the standard deviation did not exceed $\pm 0.1 \mathrm{mN} / \mathrm{m}$. The measurements were made over a wide range of concentrations and temperatures.

2.3. Conductivity Measurement. The conductance of the aqueous solution of the material depends upon the number and size of the molecules of the solute. Therefore, this technique is considered to be cheap but also reliable and sensitive to micellization of the copolymers. Therefore, this technique has been employed for the measurement of MC
TABLE 1: Molecular weight and degree of dispersity of the samples of the copolymers.

\begin{tabular}{lccc}
\hline S. number & Polymer sample & ${\mathrm{Mn} 10^{-4}(\mathrm{~g} / \mathrm{mol})}_{1}$ & PDI \\
\hline 1 & PS61-b-PEO113 & $1.13 \pm 0.025$ & $1.29 \pm 0.02$ \\
2 & PS72-b-PEO113 & $1.25 \pm 0.028$ & $1.21 \pm 0.02$ \\
3 & PS88-b-PEO113 & $1.42 \pm 0.032$ & $1.18 \pm 0.02$ \\
\hline
\end{tabular}

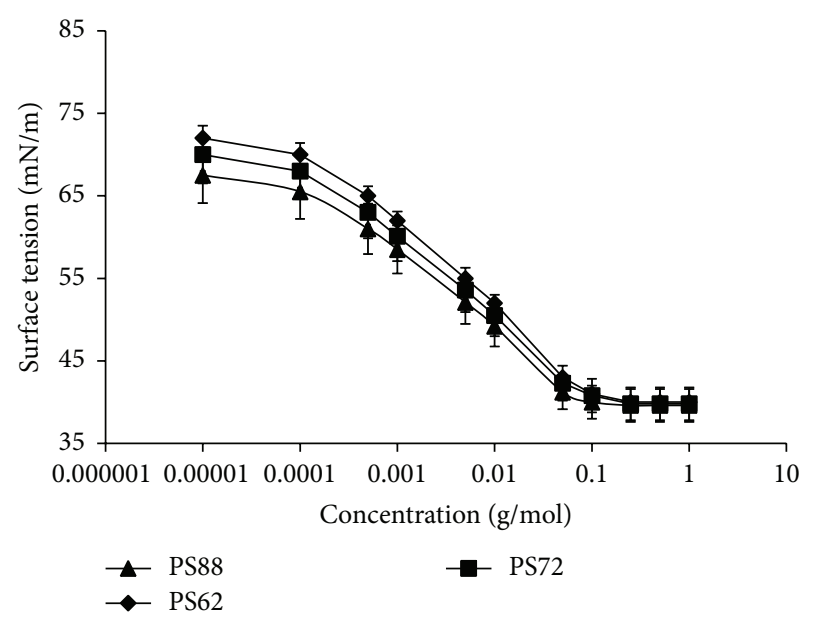

FIGURE 1: Surface tension of polymer samples as a function of polymer concentration, dissolved in water and measured at $25^{\circ} \mathrm{C}$.

of the copolymers. For the purpose, InoLab 720 conductivity meter was employed. Instrument was calibrated by measuring the conductance of $0.01 \mathrm{M} \mathrm{KCl}$ standard solution at room temperature.

\section{Results and Discussion}

The synthesized copolymers were characterized by using NMR and GPC as discussed in [19]. The results obtained concluded that these were diblock copolymers with different block lengths of styrene. The detailed results are reported in Table 1 .

There are different techniques by which the amphiphilic character of the surfactant and block copolymer can be measured, among these the surface tension $(\gamma)$ is considered to be the best conventional method used for the purpose [21]. The dependence of surface tension $(\gamma)$ on concentration of copolymers in aqueous solutions measured at $25^{\circ} \mathrm{C}$ is depicted in Figure 1. The figure indicates that the surface tension curves are according to expectations [20] and it can be divided into three parts. The first part is that in which the surface tension decreases slowly with the increase in concentration of the polymer. In this range of concentration the copolymers exist in molecular state and no aggregation takes place. However, if the concentration is increased beyond certain limit or, in the second part of the curve, the surface tension decreases with high rate with the increase in concentration of copolymer. The concentration at which the surface tension decreases fast is termed as critical association concentration. In this region, the molecular association takes 


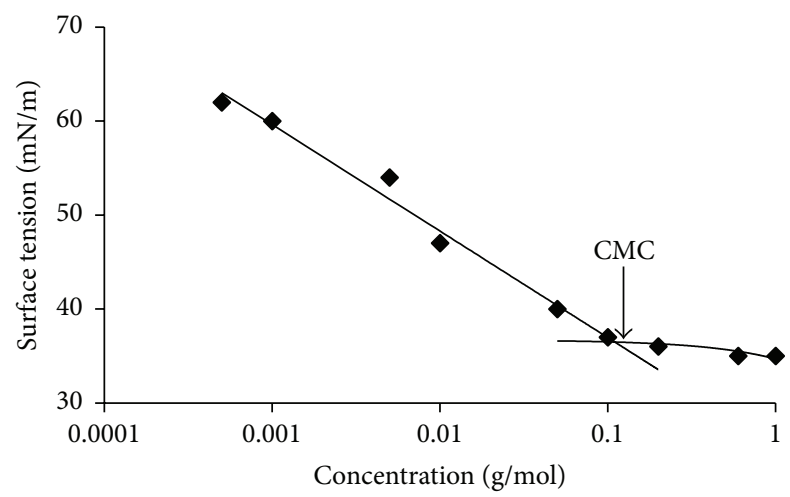

FIgURE 2: Schematic representation of determining CMC of samples.

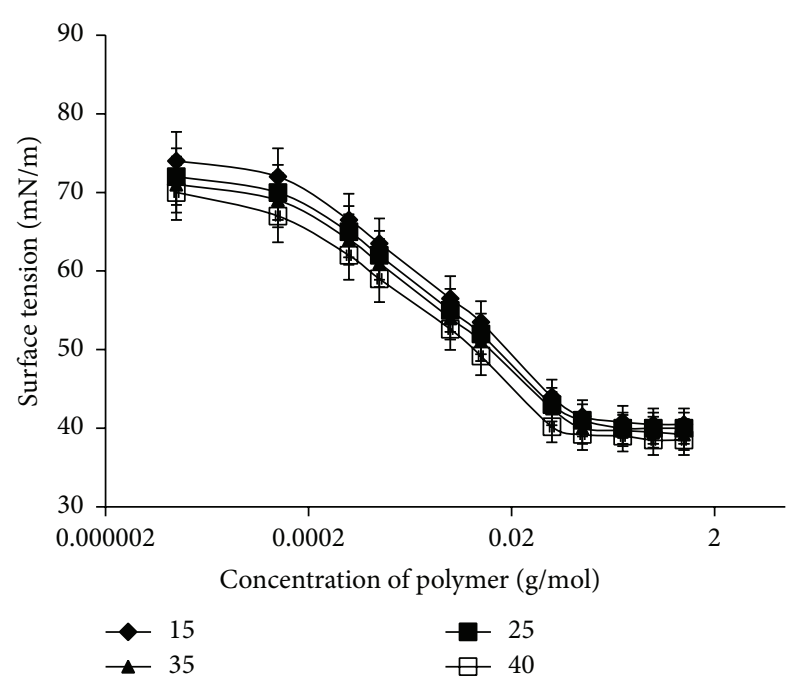

FIGURE 3: Surface tension of PS62 as a function of its concentration, determined at various temperatures.

place and molecules try to come to air/water interface and ultimately, the surface becomes saturated and micellization takes place. The concentration at which micellization takes place is known as critical micelles concentration (CMC); however, if the concentration is further increased (part three of the curve) it does not significantly affect the surface tension and it becomes constant [22]. To get the precise value of CMC, the data was divided into two portions and straight line was drawn through both data points. The equations for these straight lines were obtained and the intersection point was obtained by solving these equations as displayed in Figure 2. This intersection point was considered as CMC $[3,20-24]$. The surface tension was also measured at different temperatures and CMC was obtained at these temperatures (Figure 3). The results so obtained are displayed in Figure 4 as a function of temperature for all the samples. The results conclude that the CMC decreases with the increase in length of styrene (hydrophobic) block as observed by others for various materials [22-26]. This is due to the fact that with the increase in length of the styrene block the interactions between the polymer and the solvent become low and hence

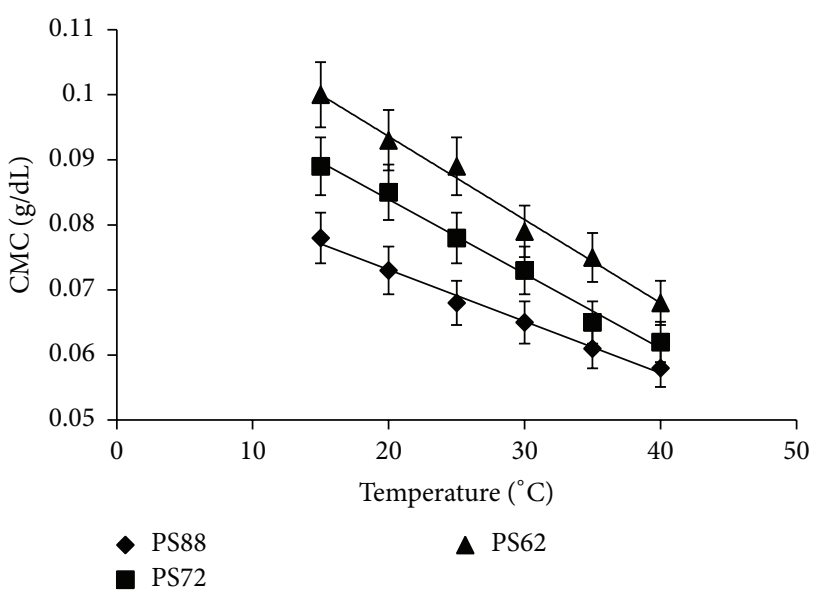

FIGURE 4: CMC of various polymer samples as a function of temperature.

cannot hold the polymer in molecular state. Therefore, the micellization takes place at lower concentration. This is the reason that the decrease in surface is high for longer styrene block. Figure 3 indicates that the surface tension decreases with the increase in temperature of the system as the solvent quality deteriorates with the increase in temperature. The CMC determined from these curves is displayed in Figure 4, which indicates that it decreases with the increase in temperature of the system for all the copolymer systems [24-26]. The figure also indicates that the decreasing rate of $\mathrm{CMC}$ with the temperature was high for copolymers with short styrene block and vise versa.

A number of well-established models can be used to explain the association behavior of amphiphilic compounds. Using the earlier established concepts we have applied the closed association model [22-24]. According to this model, for micellization with narrow distribution of aggregation number $(N)$, the equilibrium between copolymers unimers molecules $(A)$ and micelles $\left(A_{N}\right)$ can be written as $[24,27]$

$$
A \longleftrightarrow \frac{1}{N} A_{N} K_{c}=\frac{A_{\mathrm{aq}}}{N[A]_{\mathrm{aq}}} .
$$

The concentration of copolymers/surfactant is taken in mole $\mathrm{dm}^{-3}$ and $K_{c}$ is the equilibrium constant.

Hall in his detailed study showed that when the association number $N$ is very large, (1) becomes [27]

$$
K_{c}=\frac{1}{A_{\mathrm{aq}}},
$$

or

$$
K_{c}=\frac{1}{\mathrm{CMC}}
$$

$[A]_{\mathrm{aq}}$ is considered to be the critical micelle concentration (CMC). The change in standard Gibbs free energy of micellization per mole of copolymer unimers can be related to CMC by applying some important relationship [28]:

$$
\Delta G_{\text {mic }}^{\circ}=-R T \ln K_{c} .
$$




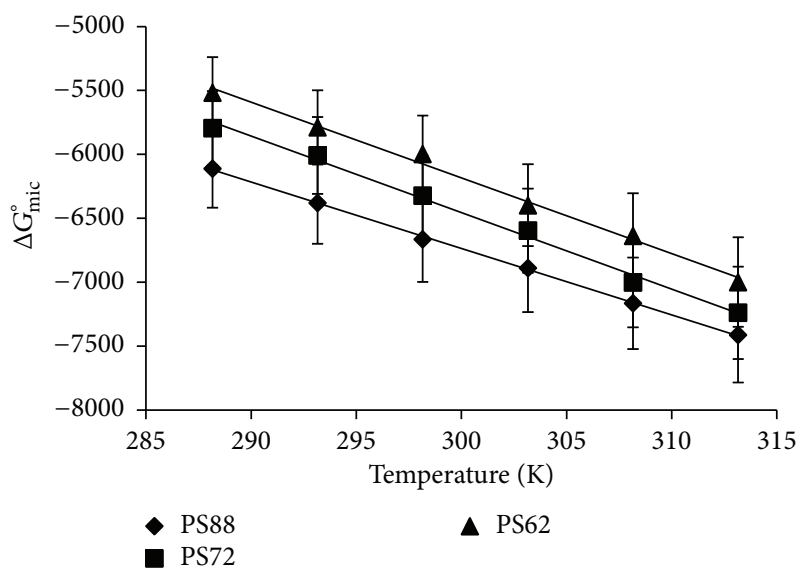

FIGURE 5: Free energy of micellization as a function of temperature for all the three polymer samples.

Inserting the value of $K_{c}$ we get

$$
\Delta G_{\text {mic }}^{\circ}=R T \ln \mathrm{CMC} \text {, }
$$

where $R$ is Gas constant and $T$ is absolute temperature.

The values of $\Delta G_{\text {mic }}^{\circ}$ were determined by using (5) and plotted in Figure 5. It shows that free energy is negative and decreases (becomes more negative) with the increase in temperature with almost the same rate for all the polymer samples. This means that the micellization process is spontaneous and the rate of micellization increases with the increase in temperature.

The standard enthalpy change of micellization processes is given by [29-34]

$$
\Delta H_{\mathrm{mic}}^{\circ}=-R \frac{\left[d \ln K_{c}\right]}{d(1 / T)} .
$$

To relate $\Delta H_{\text {mic }}^{\circ}$ to CMC, (6) can be modified to the following relation by putting the value of $K_{c}$ from (2) and we can get

$$
\Delta H_{\text {mic }}^{\circ}=R \frac{[d \ln \mathrm{CMC}]}{d(1 / T)} .
$$

Using (7), the standard change in enthalpy of micellization for all copolymer samples was obtained from the slope of the plots of In CMC versus inverse of temperature; such a typical plot for copolymers is shown in Figure 6. The values so obtained are displayed in Figure 8, which indicates that the values are positive and highest for PS62 and lowest for PS88. This means that micellization process of PS88 is much favored as compared to PS62 due to longer chain of polystyrene and this polymer will be of more hydrophobic nature than the former due to the presence of high contents of PS. Thus our result suggest that anything, for example, longer hydrophobic block length, more hydrophobic end group, and increase in temperature, raises the hydrophobicity of the copolymer and hence increasing the association ability of the polymer.

The enthalpy of micellization, $\Delta H_{\text {mic }}^{\circ}$, which is positive for all the copolymers and at all temperatures, indicated the endothermic nature of micellization and was driven by

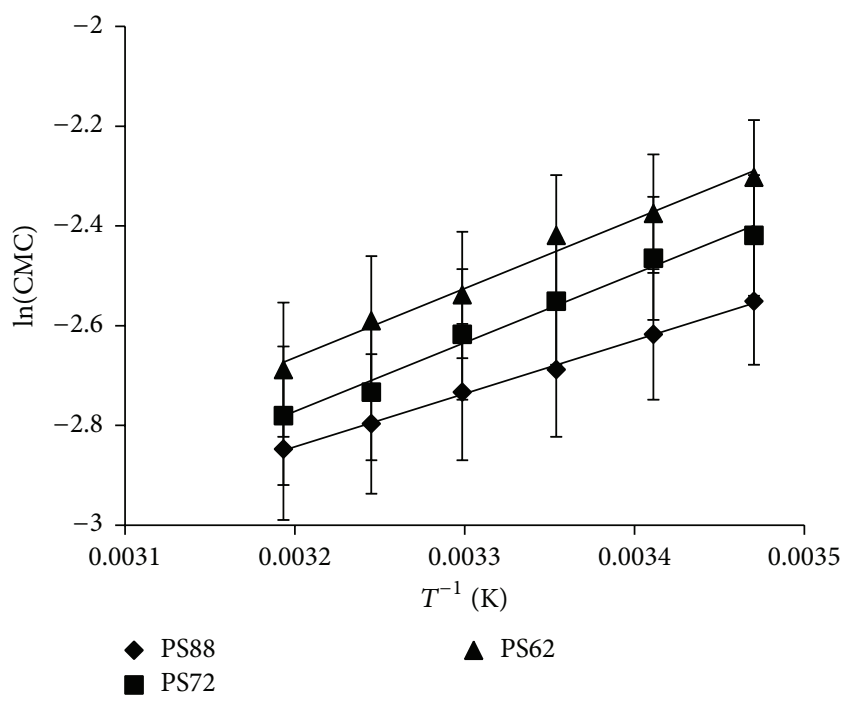

FIGURE 6: $\log$ of CMC as a function of reciprocal of temperature (in Kelvin) at which the CMC was measured.

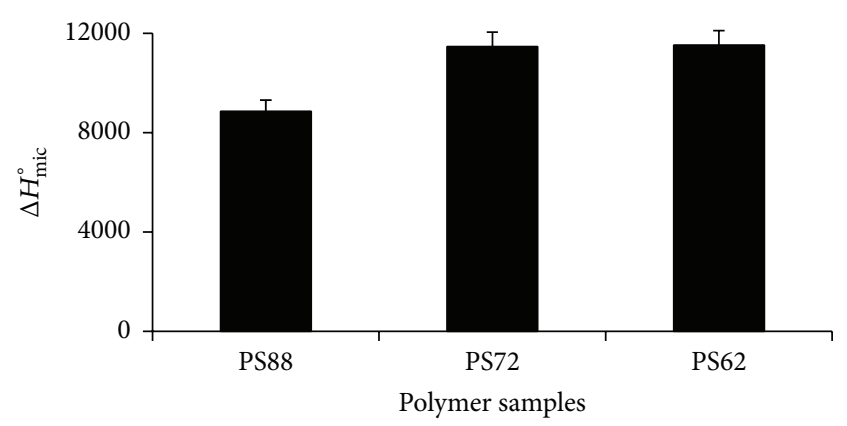

FIgURE 7: $\Delta H^{\circ}$ micellization for various polymer samples.

decreasing polarity of PEO and PS chains in water (Figure 7). Energy is required to overcome the interactions of water with copolymer's unimers and to bring them from hydrophilic bulk into relatively hydrophobic core of the micelle.

In addition to micellar thermodynamic parameters, surface tensiometric measurements have also been applied to get information about the adsorption of the copolymer at air/water interface. For this reason, the premicellar region of surface tension $(\gamma)$ versus logarithm of copolymer concentration $(\ln C)$ plots was used as shown in Figure 1. Such study of the interfacial properties of amphiphilic block copolymers in solutions provides us with information about solute-solute and solute-solvent interactions [22, 23]. To calculate the surface excess concentration, $\left(\Gamma_{\max }\right)$, of the copolymer at the air/water interface as compared to that in bulk of solution, we have applied Gibbs adsorption isotherm [21, 28]. From the slope of the surface tension curve (linear line immediate before CMC), surface excess concentration at the surface of the solution can be measured by using Gibbs formalism $[29,30]$ :

$$
\Gamma_{\max }=-\frac{1}{R T}\left(\frac{\partial \gamma}{\partial \ln C}\right)_{T, p}
$$




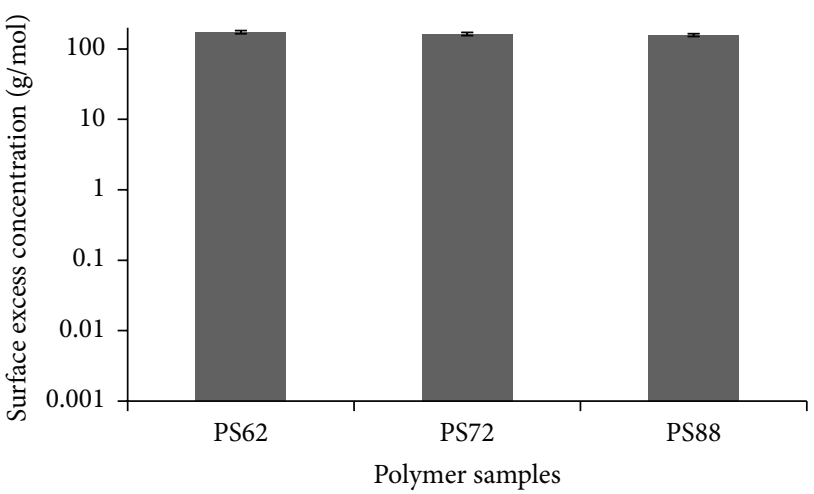

(a)

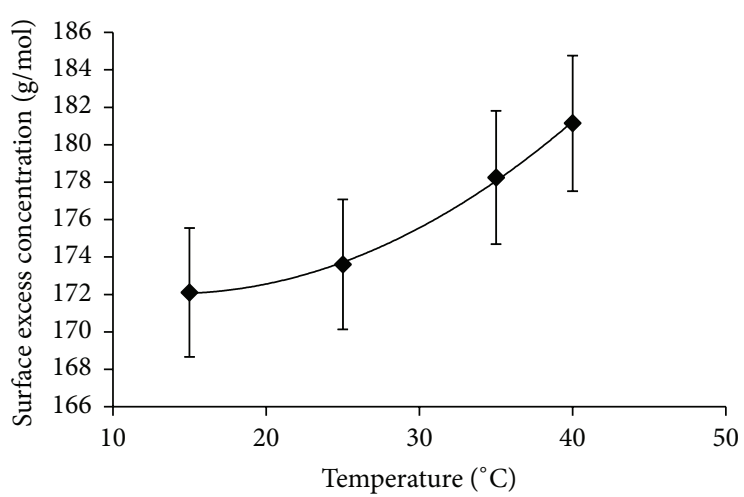

(b)

FIgURE 8: Surface excess concentration of polymer samples as a function of (a) polymer nature and (b) temperature for polymer PS62.

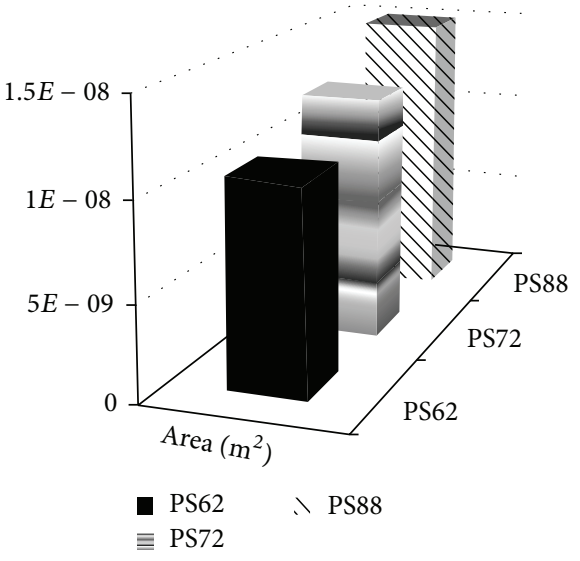

(a)

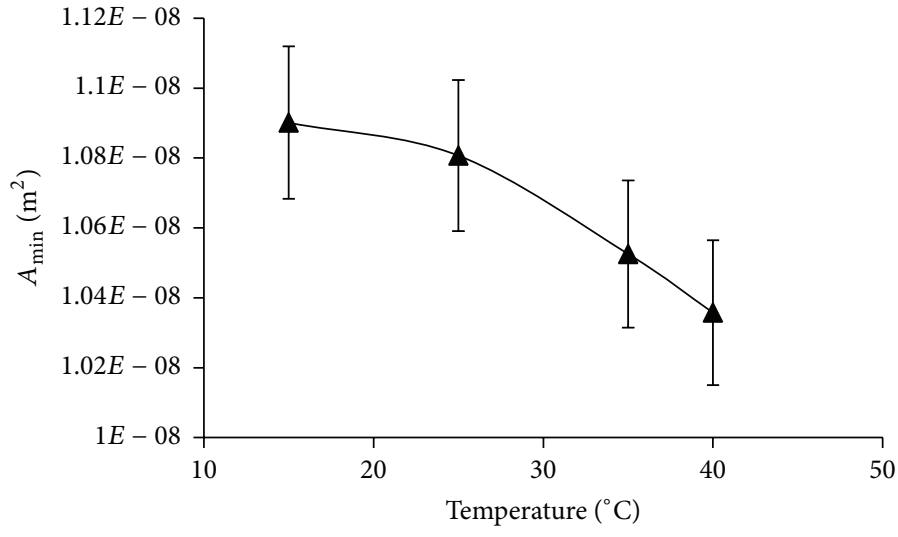

(b)

FIGURE 9: Minimum area per molecules (a) of various polymer samples measured at $25^{\circ} \mathrm{C}$ and (b) as a function of temperature for PS62 sample.

Here $\Gamma_{\max }$ is the surface excess concentration, $C$ is the copolymer concentration, $R$ is the gas constant, and $T$ is the absolute temperature.

For the purpose, the slopes were determined and $\Gamma_{\max }$ was calculated using (8). The values so obtained are displayed in Figure 8. The figure indicates that $\Gamma_{\max }$ decreases with the increase in contents of styrene. This can be attributed to increase in hydrophobicity and molecular mass of the polymer sample. Most probably, with the increase in chain length, the intermolecular interactions increase which retain the polymer in the water. On the other hand, $\Gamma_{\max }$ was decreased with the increase in temperature (Figure 8(b)). It is due to the fact that the $\mathrm{CMC}$ decreases with the temperature and the polymer comes to the surface with the increase in temperature. We can say that the decrease in solubility and increase in hydrophobicity of the copolymer samples with the increase in temperature lead to increase in $\Gamma_{\max }$ with the temperature. From the surface excess concentration, another important parameter, that is, minimum area per molecule
( $\left.A_{\text {min }}\right)$, can be calculated by using the following equation as purposed in $[33,34]$ :

$$
A_{\text {min }}=\frac{10^{18}}{N_{A} \Gamma_{\max }} .
$$

Here $N_{A}$ is Avogadro number.

$A_{\text {min }}$ was determined using (9) for all the copolymers samples and has been displayed in Figure 9. The figure indicates that surface area increases with the increase in chain length of styrene. It is according to expectations as the bigger the molecules are the more the surface area will be if solvent quality and temperature are the same. The temperature has also effect over the surface area and it decreases with the increase in temperature as displayed in Figure 9(b). It is due to the fact that with the increase in temperature the polymer conformation changes [34].

The other technique applied for the determination of $\mathrm{CMC}$ was the application of conductance. In this respect 


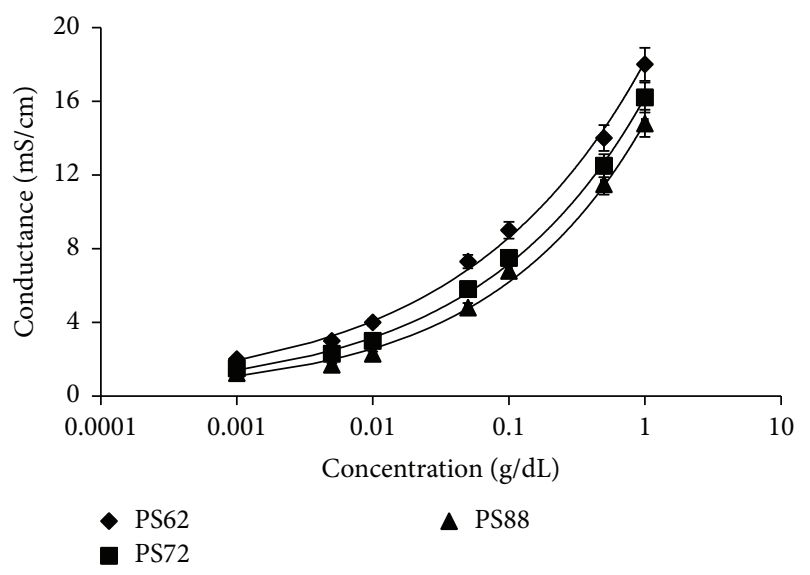

FIGURE 10: Conductance of various polymer samples measured in water as a function of their concentration at $25^{\circ} \mathrm{C}$.

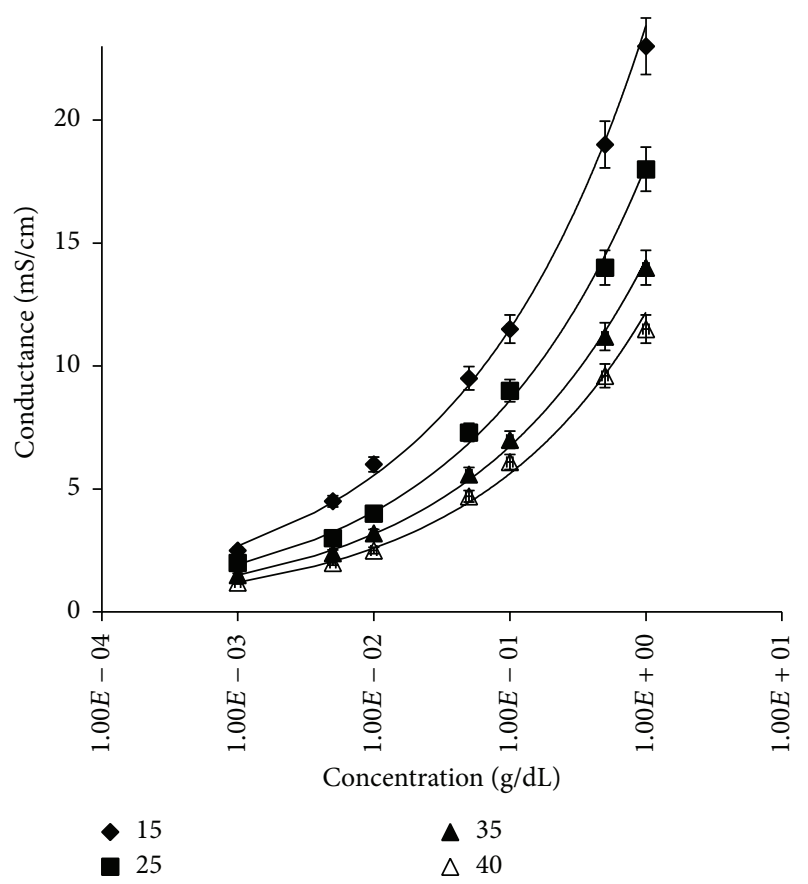

Figure 11: Conductance of polymer sample PS62 as a function of polymer concentration, measured at various temperatures.

the conductance was measured for all the three samples as a function of polymer nature, their concentration, and temperature of the system. It was noted that the conductance was increased with the increase in concentration of polymer samples. All the samples showed a similar and expected trend and the conductance was less for samples having longer chains and vice versa (Figure 10) [19]. This trend can be attributed to slow movement/small diffusion rate of longer chain polymers. The conductance of the polymer samples measured as a function of temperature and polymer concentration is displayed in Figure 11. It indicates that the conductance was decreased with the increase in temperature. However, the curves showed a similar trend for all temperatures. This trend is attributed to change in

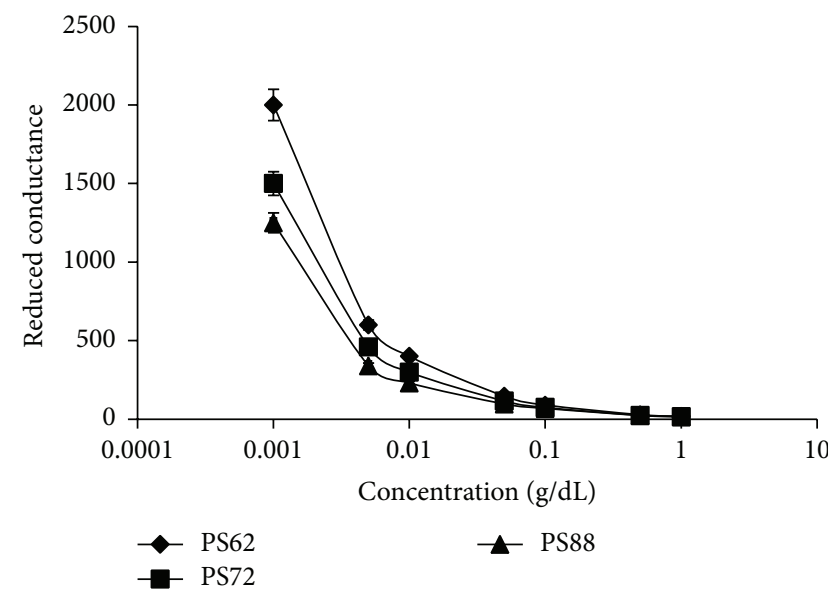

FIGURE 12: Reduced conductance of various polymer samples as a function of concentration.

conformation of polymers with the variation in temperature. As it can be noted that it is very difficult to get the value of CMC from such graphs precisely so we have plotted the data in the form of reduced (= conductance/concentration) conductance (Figure 12). It can be noted that now it is easy to get the accurate value of CMC. The results obtained in this way concluded that both techniques gave the same results for $\mathrm{CMC}$ and hence the results were reproducible and precise.

\section{Competing Interests}

The authors declare that they have no competing interests.

\section{Acknowledgments}

This paper was funded by the Deanship of Scientific Research (DRS) of King Abdulaziz University, Jeddah (Grant no. 247002-D1434). The authors therefore acknowledge the DRS for the technical and financial support.

\section{References}

[1] K. Mortensen, "Structural studies of aqueous solutions of PEOPPO-PEO triblock copolymers, their micellar aggregates and mesophases; a small-angle neutron scattering study," Journal of Physics Condensed Matter, vol. 8, no. 25, pp. A103-A124, 1996.

[2] P. Alexandridis, J. F. Holzwarth, and T. A. Hatton, "Micellization of poly(ethylene oxide)-poly(propylene oxide)-poly(ethylene oxide) triblock copolymers in aqueous solutions: thermodynamics of copolymer association," Macromolecules, vol. 27, no. 9, pp. 2414-2425, 1994.

[3] C. Booth and D. Attwood, "Effects of block architecture and composition on the association properties of poly(oxyalkylene) copolymers in aqueous solution," Macromolecular Rapid Communications, vol. 21, no. 9, pp. 501-527, 2000.

[4] Y. Jianjun, X. Zushun, C. Shiyuan, and F. Linxian, “The aggregation of polystyrene- $b$-poly(ethylene oxide)- $b$-polystyrene triblock copolymers in aqueous solution," European Polymer Journal, vol. 38, no. 8, pp. 1537-1546, 2002. 
[5] D. H. Richards and M. Szwarc, "Block polymers of ethylene oxide and its analogues with styrene," Transactions of the Faraday Society, vol. 55, pp. 1644-1650, 1959.

[6] M. Szwarc and M. Van Beylen, Ionic Polymerization and Living Polymers, vol. 82, Chapman \& Hall, New York, NY, USA, 1993.

[7] M. Morton, Anionic Polymerization: Principles and Practice, vol. 4, Academic Press, New York, NY, USA, 1983.

[8] E. J. Goethals, Cationic Polymerization and Related Processes, Academic Press, New York, NY, USA, 1984.

[9] O. W. Webster, W. R. Hertler, D. Y. Sogah, W. B. Farnham, and T. V. RajanBabu, "Group-transfer polymerization. 1. A new concept for addition polymerization with organosilicon initiators," Journal of the American Chemical Society, vol. 105, no. 17, pp. 5706-5708, 1983.

[10] Y. Doi and T. Keii, "Synthesis of "living" polyolefins with soluble Ziegler-Natta catalysts and application to block copolymerization," in Chromatography/Foams/Copolymers, vol. 73-74 of Advances in Polymer Science, pp. 201-248, Springer, Berlin, Germany, 1986.

[11] K. P. Matyjaszewski, T. E. Patten, and J. Xia, "Controlled/'living' radical polymerization. Kinetics of the homogeneous atom transfer radical polymerization of styrene," Journal of the American Chemical Society, vol. 119, no. 4, pp. 674-680, 1997.

[12] S. G. Gaynor and K. Matyjaszewski, "Step-growth polymers as macroinitators for 'iving' radical polymerization: synthesis of ABA block copolymers," Macromolecules, vol. 30, no. 14, pp. 4241-4243, 1997.

[13] X. He, H. Zhang, D. Yan, and X. Wang, "Synthesis of side-chain liquid-crystalline homopolymers and triblock copolymers with p-methoxyazobenzene moieties and poly(ethylene glycol) as coil segments by atom transfer radical polymerization and their thermotropic phase behavior," Journal of Polymer Science Part A: Polymer Chemistry, vol. 41, no. 18, pp. 2854-2864, 2003.

[14] S. Cheng, Z. Xu, J. Yuan et al., "Synthesis and characterization of polystyrene-b-poly(ethylene oxide)-b-polystyrene triblock copolymers by atom-transfer radical polymerization," Journal of Applied Polymer Science, vol. 77, no. 13, pp. 2882-2888, 2000.

[15] B. Reining, H. Keul, and H. Höcker, "Amphiphilic block copolymers comprising poly(ethylene oxide) and poly(styrene) blocks: synthesis and surface morphology," Polymer, vol. 43, no. 25, pp. 7145-7154, 2002.

[16] K. Ibrahim, A. Salminen, S. Kat Holappa et al., "Preparation and characterization of polystyrene-poly(ethylene oxide) amphiphilic block copolymers via atom transfer radical polymerization: potential application as paper coating materials," Journal of Applied Polymer Science, vol. 102, no. 5, pp. 4304-4313, 2006.

[17] W. Tang and K. Matyjaszewski, "Effects of initiator structure on activation rate constants in ATRP," Macromolecules, vol. 40, no. 6, pp. 1858-1863, 2007.

[18] W. Tang and K. Matyjaszewski, "Kinetic modeling of normal ATRP, normal ATRP with $\left[\mathrm{Cu}^{I I}\right]_{0}$, reverse ATRP and SR\&NI ATRP," Macromolecular Theory and Simulations, vol. 17, no. 7-8, pp. 359-375, 2008.

[19] M. Nawaz, M. K. Baloch, G. J. Price, I. Ud-Din, and E.-S. E.-B. El-Mossalamy, "Synthesis, association and surface morphology of poly (ethylene oxide)-polystyrene block copolymer," Journal of Polymer Research, vol. 20, article 180, 2013.

[20] F. Ahmad, M. K. Baloch, M. Jamil, and Y. J. Jeon, "Characterization of polystyrene-b-poly(ethylene oxide) diblock copolymer and investigation of its micellization behavior in water," Journal of Applied Polymer Science, vol. 118, no. 3, pp. 1704-1712, 2010.
[21] C. Holmberg, S. Nilsson, S. K. Singh, and L.-O. Sundelöf, "Hydrodynamic and thermodynamic aspects of the SDSEHEC-water system," The Journal of Physical Chemistry, vol. 96, no. 2, pp. 871-876, 1992.

[22] A. Rauf, M. K. Baloch, and G. F. Durrani, "Effect of molecular mass of polyethylene oxide over its aggregation behavior," Journal of the Chemical Society of Pakistan, vol. 32, no. 2, pp. 168-171, 2010.

[23] E. Castro, P. Taboada, and V. Mosquera, "Cosolvent effects on the micellization of oxyphenyl(copoly)ethylene oxide copolymers in aqueous solution," Journal of Physical Chemistry B, vol. 110, no. 26, pp. 13113-13123, 2006.

[24] G. Riess, "Micellization of block copolymers," Progress in Polymer Science, vol. 28, no. 7, pp. 1107-1170, 2003.

[25] A. Khan and M. Siddiq, "Surface activity and micellar behavior of dimethylamino- and trimethylammonium-tipped oxyethylene-oxybutylene diblock copolymers in aqueous media," Journal of Applied Polymer Science, vol. 118, no. 6, pp. 3324-3332, 2010.

[26] P. Alexandridis and T. Alan Hatton, "Poly(ethylene oxide)poly(propylene oxide )-poly (ethylene oxide) block copolymer surfactants in aqueous solutions and at interfaces: thermodynamics, structure, dynamics, and modeling," Colloids and Surfaces: A Physicochemical and Engineering Aspects, vol. 96, no. 1-2, pp. 1-46, 1995.

[27] A. Khan, I. Bibi, S. Pervaiz, K. Mahmood, M. Siddiq, and M. Siddiq, "Surface tension, density and viscosity studies on the associative behaviour of oxyethylene-oxybutylene diblock copolymers in water at different temperatures," International Journal of Organic Chemistry, vol. 2, no. 1, pp. 82-92, 2012.

[28] D. G. Hall, "Nonionic surfactants physical chemistry," in Phase Behavior and Association, B. Chu and M. J. Schick, Eds., pp. 23247, Marcel Dekker, New York, NY, USA, 1987.

[29] T. P. Lodge, "Block copolymers: past successes and future challenges," Macromolecular Chemistry and Physics, vol. 204, no. 2, pp. 265-273, 2003.

[30] P. Alexandridis, V. Athanassiou, S. Fukuda, and T. A. Hatton, "Surface activity of poly(ethylene oxide)-block-poly(propylene oxide)-block-poly(ethylene oxide) copolymers," Langmuir, vol. 10, no. 8, pp. 2604-2612, 1994.

[31] P. Lo Nostro and G. Gabrielli, "Temperature and subphase effects on aliphatic alcohol films at the air-water interface," Langmuir, vol. 9, no. 11, pp. 3132-3137, 1993.

[32] S. S. Soni, N. V. Sastry, A. K. Patra, J. V. Joshi, and P. S. Goyal, "Surface activity, SANS, and viscosity studies in aqueous solutions of oxyethylene and oxybutylene $\mathrm{Di}$ - and triblock copolymers," The Journal of Physical Chemistry B, vol. 106, no. 50, pp. 13069-13077, 2002.

[33] S. S. Soni, N. V. Sastry, V. K. Aswal, and P. S. Goyal, "Micellar structure of silicone surfactants in water from surface activity, SANS and viscosity studies," The Journal of Physical Chemistry $B$, vol. 106, no. 10, pp. 2606-2617, 2002.

[34] M. J. Rosen, A. W. Cohen, M. Dahanayake, and X. Y. Hua, "Relationship of structure to properties in surfactants. 10. Surface and thermodynamic properties of 2-dodecyloxypol$\mathrm{y}$ (ethenoxyethanol)s, $\mathrm{C}_{12} \mathrm{H}_{25}\left(\mathrm{OC}_{2} \mathrm{H}_{4}\right)_{x} \mathrm{OH}$, in aqueous solution," The Journal of Physical Chemistry, vol. 86, no. 4, pp. 541$545,1982$. 

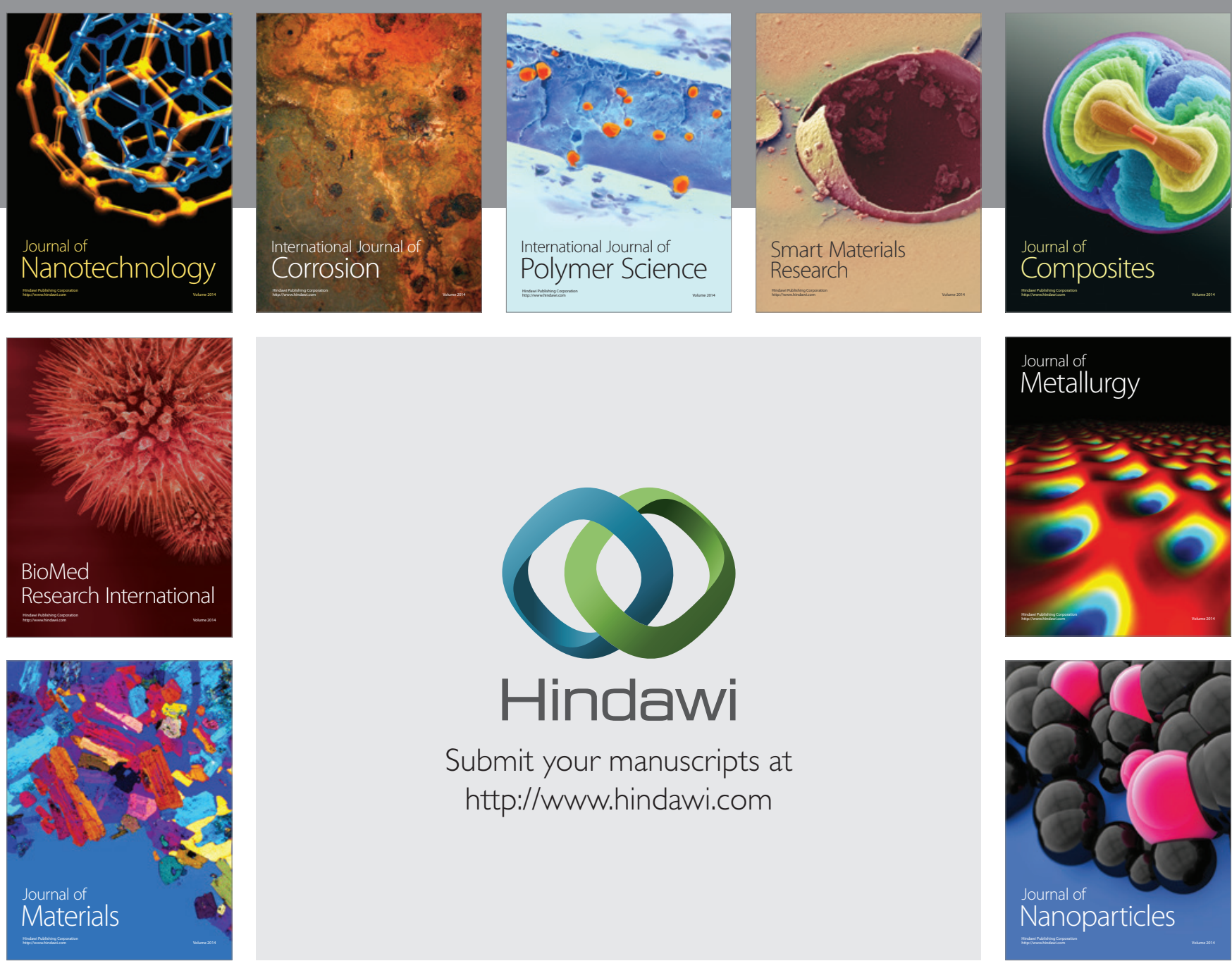

\section{Hindawi}

Submit your manuscripts at

http://www.hindawi.com

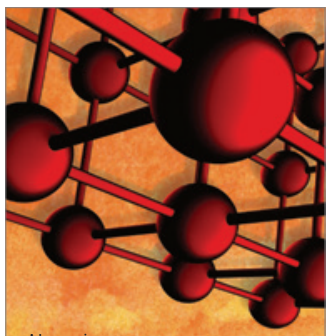

Materials Science and Engineering
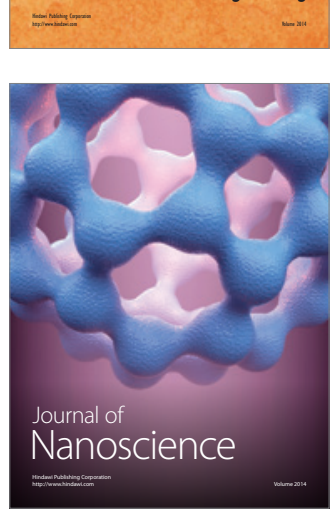
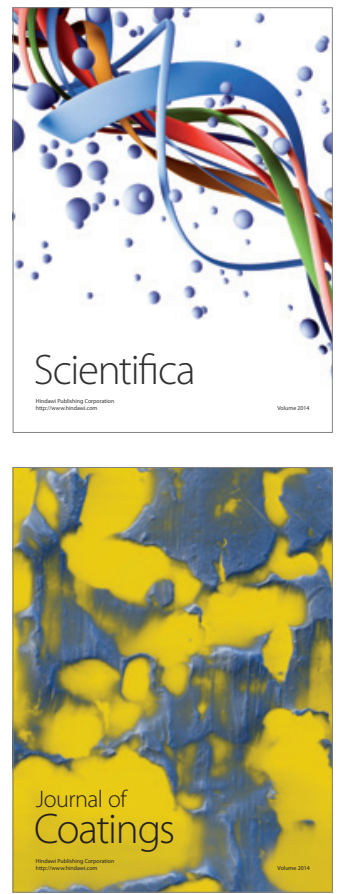
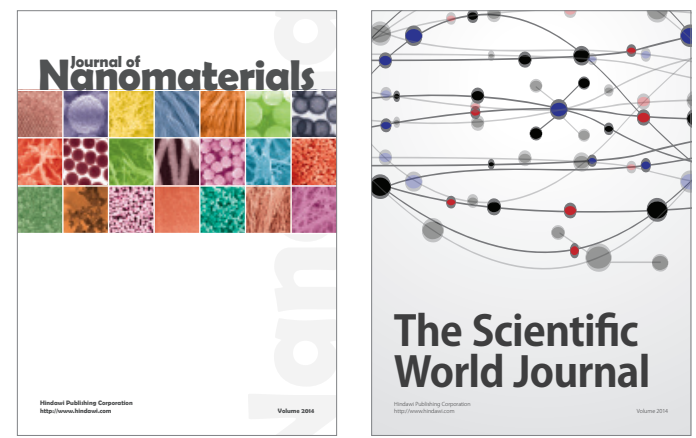

The Scientific World Journal
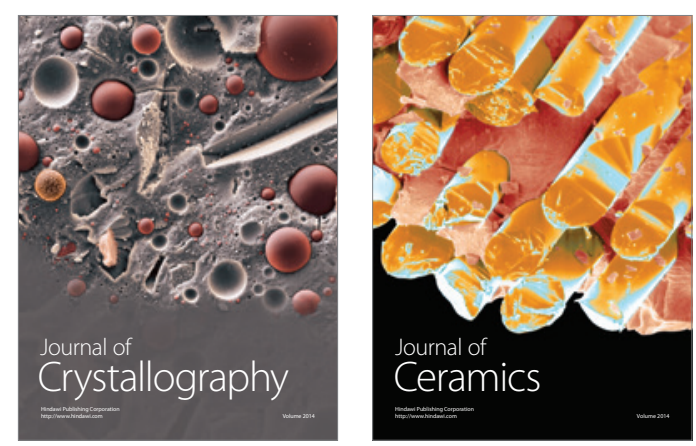
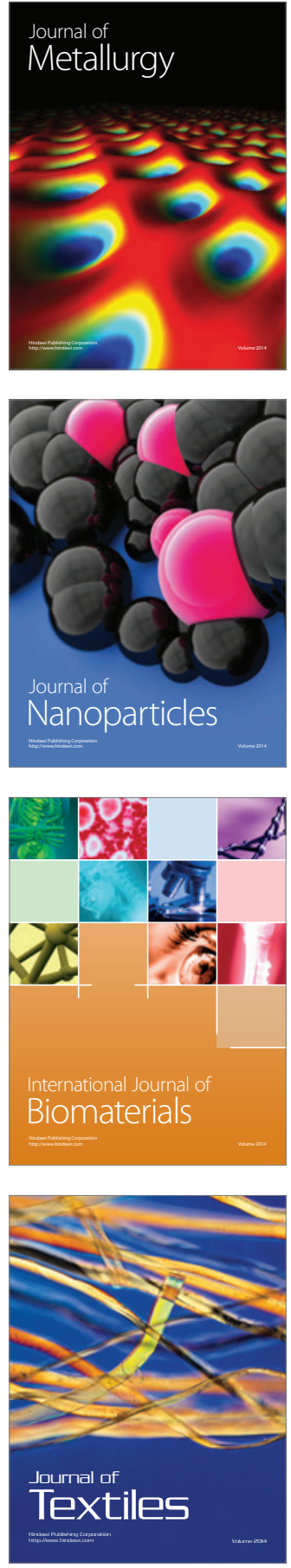